\title{
Angiotensin II, Vasopressin, and Collagen-IV Expression in the Subfornical Organ in a Case of Syndrome of Inappropriate ADH
}

\author{
Emilia M. Carmona-Calero, ${ }^{1,2}$ Juan M. González-Toledo, ${ }^{1}$ Leandro Castañeyra-Ruiz, ${ }^{1,3}$ \\ Ibrahim González-Marrero, ${ }^{1}$ María Castañeyra-Ruiz, ${ }^{2}$ Héctor de Paz-Carmona, ${ }^{2}$ \\ Agustín Castañeyra-Ruiz, ${ }^{2}$ Nélida Rancel-Torres, ${ }^{1}$ and Agustín Castañeyra-Perdomo, ${ }^{1,2}$ \\ ${ }^{1}$ Departamento de Anatomía, Anatomía Patológica e Histología, Facultad de Medicina, Universidad de La Laguna, \\ Ofra s/n, 38071 La Laguna, Tenerife, Spain \\ ${ }^{2}$ Departamento de Biotecnología, Instituto de Investigación y Ciencias de Puerto del Rosario, C/Tenerife 35, \\ 35600 Puerto del Rosario, Fuerteventura, Isla Canarias, Spain \\ ${ }^{3}$ Departamento de Farmacología, Facultad de Medicina, Universidad de La Laguna, Ofra s/n, 38071 La Laguna, \\ Tenerife, Islas Canarias, Spain
}

Correspondence should be addressed to Agustín Castañeyra-Perdomo; acastaneyra@gmail.com

Received 28 May 2014; Revised 28 July 2014; Accepted 19 August 2014; Published 6 November 2014

Academic Editor: Carole Samango-Sprouse

Copyright (c) 2014 Emilia M. Carmona-Calero et al. This is an open access article distributed under the Creative Commons Attribution License, which permits unrestricted use, distribution, and reproduction in any medium, provided the original work is properly cited.

\begin{abstract}
The syndrome of inappropriate antidiuretic hormone (SIADH) is a disease characterized by hyponatremia and hyperosmolarity of urine where vasopressin and angiotensin II are implicated in the alteration of salt water balance and cardiovascular and blood pressure regulation. The aim of this study is to analyse the expression of substances related with cardiovascular and salt water regulation in the subfornical organ in a case of SIADH. Two brains, one taken from a 66-year-old man with SIADH and the other from a 63-year-old man without SIADH, were used. Immunohistochemical study was performed using anti-angiotensin II, antivasopressin, and anti-collagen-VI as primary antibodies. Angiotensin and vasopressin immunoreaction were found in neurons, in perivascular spaces, and in the ependymal layer in the subfornical organ in both cases. However, in the SIADH case, the angiotensin II and collagen-IV expression in the SFO were different suggesting this organ's possible participation in the physiopathology of SIADH.
\end{abstract}

\section{Introduction}

Diabetes insipidus (DI), syndrome of inappropriate antidiuretic hormone (SIADH), and syndrome cerebral saltwasting (CSW) are three pathologies with hyponatremia and hyperosmolarity and differentiation between them is important to prescribe the most appropriate treatments $[1,2]$. SIADH is a disease which is characterized by the hyponatremia and hyperosmolarity of urine [3-5]. There are well known causes for this syndrome, such as neoplasmatic processes, disorders of the central nervous system, lung diseases, and the side effects of drugs. A study [6] of a large group of patients has revealed that SIADH occurs in 3\% of patients with head and neck cancer, in $0.7 \%$ of patients with nonsmall-cell lung cancer, and in $15 \%$ of cases of small-cell lung cancer [6]. The standard therapy for SIADH is to treat the underlying malignant disease. If this is not possible or if the disease has become refractory, other treatment methods are available such as water restriction, demeclocycline therapy, or, in severe cases, infusion of hypertonic saline together with furosemide during treatment [6]. Total body water and tonicity are strictly regulated by the renal action of the antidiuretic hormone (ADH), renin-angiotensin-aldosterone system, and norepinephrine and by the thirst mechanism. Abnormalities in water balance are manifested in SIADH as sodium disturbances-hyponatremia and hypernatremia [6]. On the other hand, the presence of VAS, AGII, and TH and their implication in cardiovascular, salt water balance and blood pressure regulation have long been described in the hypothalamus in man and different animal species [7-10]. 


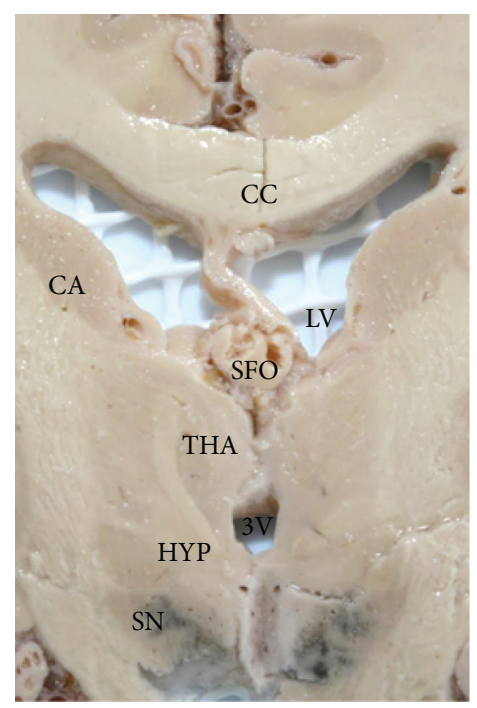

(a)

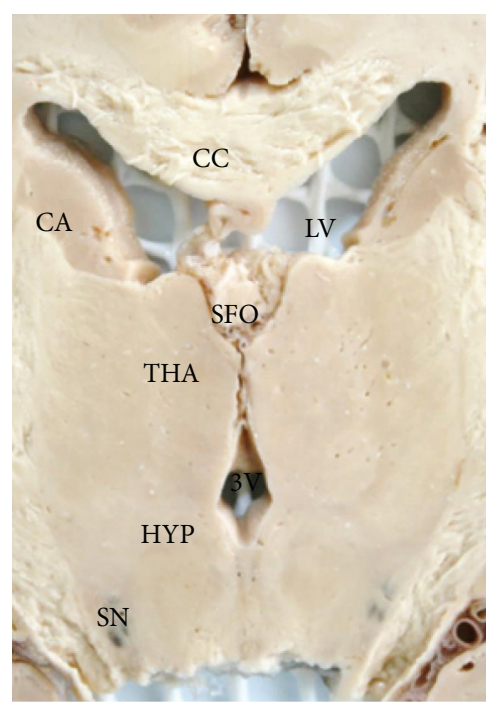

(b)

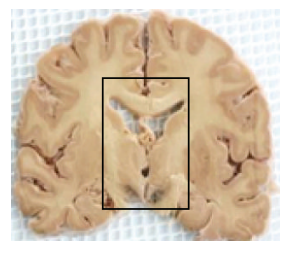

(c)

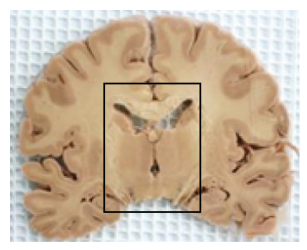

(d)

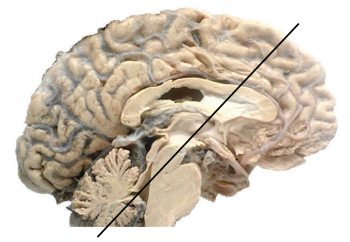

(e)

FIGURE 1: Frontal section photographs ((a), (b)) at Monroe foramen and SFO level. CA: caudate nucleus, CC: corpus callosum, HYP: hypothalamus, III: thirst ventricle, LV: lateral ventricle, SN: substantia nigra, SFO: subfornical organ, and THA: thalamus. ((a), (c)): NOSIADH case, ((b), (d)): SIADH case, (e): middle sagittal section of brain indicating cutting orientation.

Several authors have also described the detection of tyrosine hydroxylase-immunoreactivity and vasopressin mRNA and ANGII in the hypothalamus that could be related to hypertension and SIADH [11-14]. Furthermore, the subfornical organ (SFO) is a circumventricular organ located in the medial plane, below the commissure of fornix (Figures 1(a) and $1(b)$ ), which contains neurons, glia, and a dense plexus of highly fenestrated capillaries, and is covered by an ependymal layer $[15,16]$. Like other circumventricular organs, the SFO is characterized by the absence of a blood-brain barrier and the presence of tanycytes capable of transporting substances between the cerebrospinal fluid and plasma $[15,16]$. The SFO function is connected with cardiovascular regulation and salt water balance, and the increase of plasma vasopressin is regulated by the SFO angiotensinergic stimulus $[9,10,17]$. The aim of the present work is to analyse the expression of AGII, VAS, and collagen-IV (CIV), in the SFO in a case of SIADH.

\section{Methods}

The SFO of a 66-year-old man who had developed hyponatremia and presented all the symptoms of SIADH and the SFO of a 63-year-old man without SIADH, as a NOSIADH case, were studied. Non-small-cell lung cancer was the cause of death in the SIADH case; in the other case the underlying disease was cardioangiosclerosis and the patient died of multiorgan failure. Two human brains came from the Anatomy Department of the University of La Laguna.

The brain areas containing the SFO were cut in four series of coronal sections $10 \mu \mathrm{m}$ thick. The A series was stained with the Klüver-Barrera method. The B, C, and D series were processed immunohistochemically; anti-vasopressin (VAS) (ICN Biomedicals, Inc., Catal. 6\#:4717), anti-angiotensin II (AGII) [9], anti-AQP1 at 1: 1000 (Ab9566 Abcam, Cambridge, UK), and anti-collagen-IV (CIV) (SIGMA, T 2928) were 


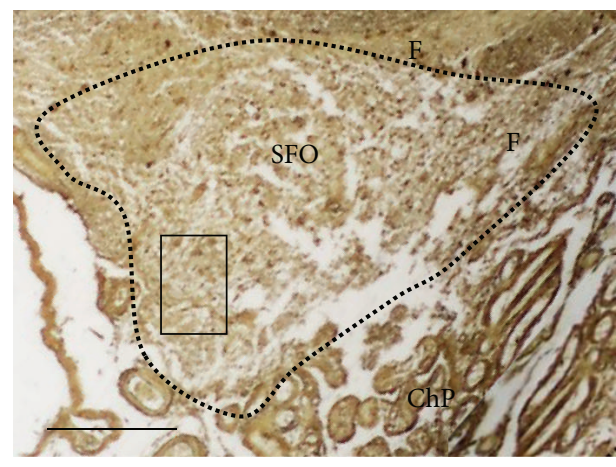

(a)

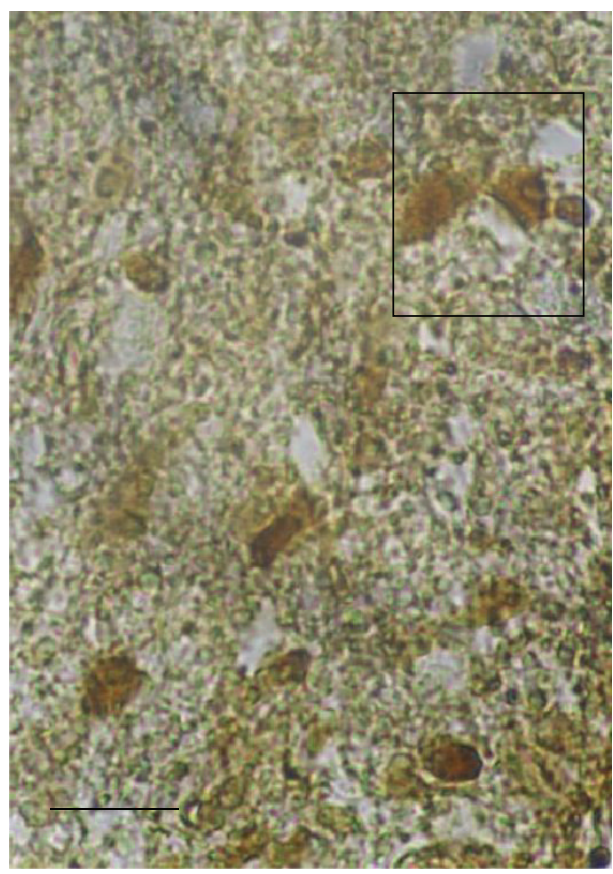

(c)

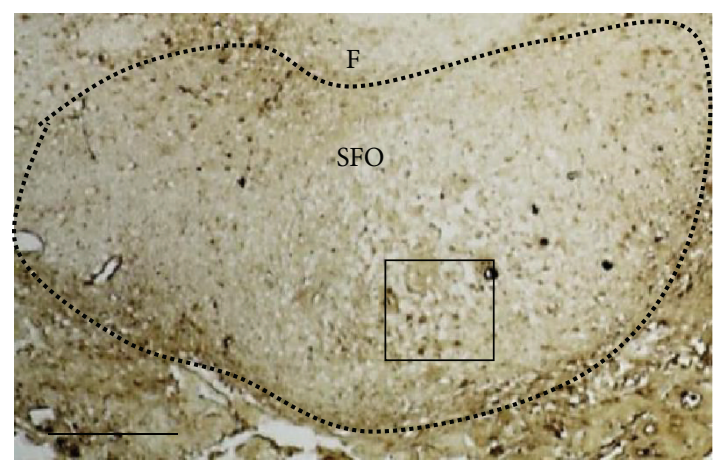

(b)

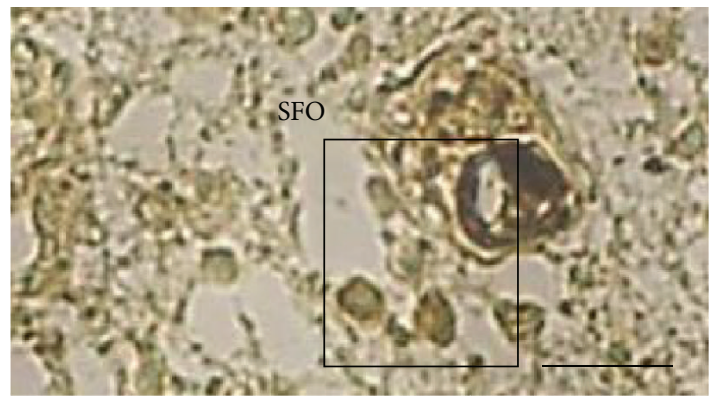

(d)

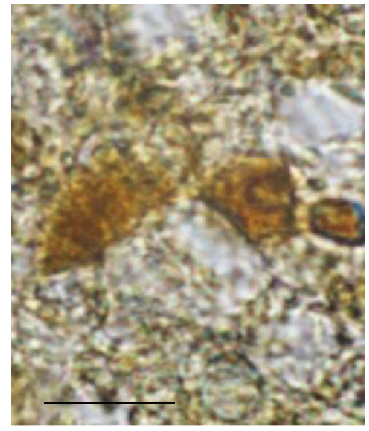

(e)

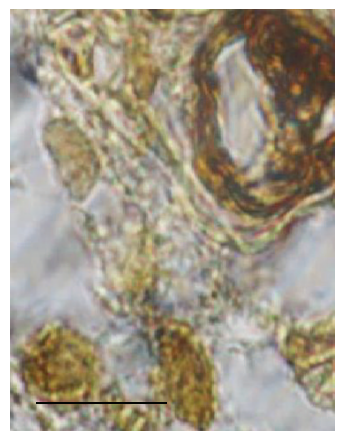

(f)

FIGURE 2: Frontal section photographs of the human SFO immunostained with anti-angiotensin II. ((a), (c), and (e)) NO-SIADH case; ((b), (d), and (f)) SIADH case. ChP: choroid plexus, F: fornix, and SFO: subfornical organ. Bar: (a), (b) = $200 \mu \mathrm{m}$; (c), (d) $=60 \mu \mathrm{m}$; (e), (f) $=20 \mu \mathrm{m}$.

used as primary antibodies. The anti-VAS, the anti-AGII, and the anti-CIV were diluted at $1: 2000,1: 100$, and $1: 1000$, respectively, in PBS-Triton with $2 \%$ normal goat serum; the incubation was for $24 \mathrm{~h}$ at room temperature, followed by the "DAKO StreptABCcomplex/HRP Duet, Mouse/Rabbit" procedure. The reaction product was visualized by diaminobenzidine reaction. Method specificity was controlled by omitting the primary antibody.

\section{Results}

3.1. Angiotensin II (AGII). AGII positive cells were located in all parts of the two SFOs and the immunoreaction was present in the perivascular spaces and the ependymal layer (Figures 2(a), 2(c), and 2(e)). In the SIADH case, the intensity of staining of labeled cells was low and redistributed, since the AGII cells were found in the dorsolateral part of the SFO and to a lesser degree in ventromedial parts. The perivascular spaces and ependymal layer also showed AGII immunoreaction in the SIADH case (Figures 2(b), 2(d), and 2(f)).

3.2. Vasopressin (VAS). In both of the two cases studied (syndrome and no-syndrome) the expression of VAS was similar in the SFOs, where the presence of clusters of labeled vasopressin cells located in the lateral part of SFO was detected. Immunoreactive material was also found in ependymal cells and perivascular spaces (Figure 3).

3.3. Collagen-IV (COL-IV). Collagen-IV was located at the SFO vessel wall of both cases (Figure 4). However, in the SIADH case, a markedly large number of vessels had irregular lumen and unfolded contours (Figures 4(b) and 4(d), arrow). 


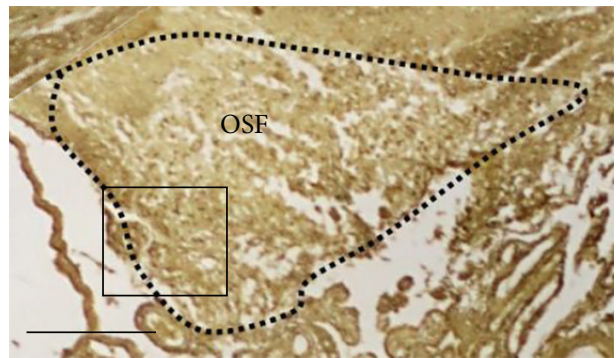

(a)

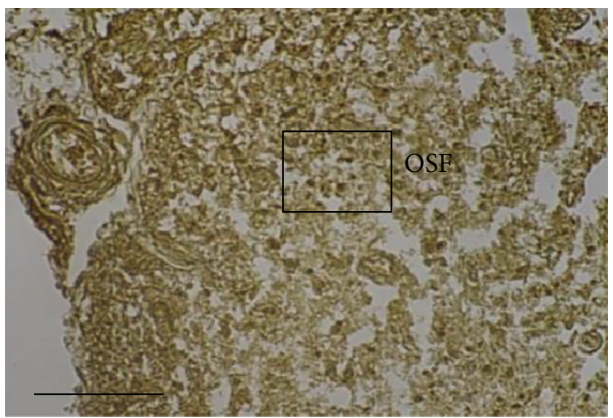

(c)

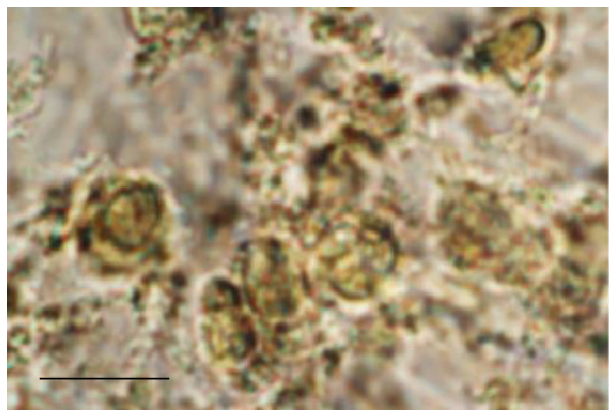

(e)

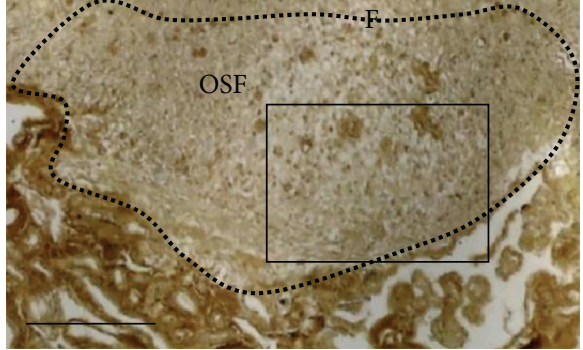

(b)

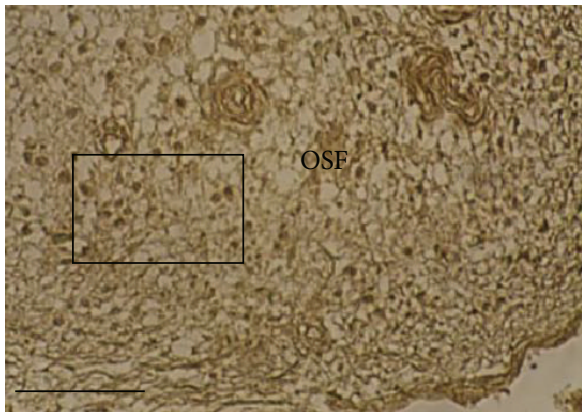

(d)

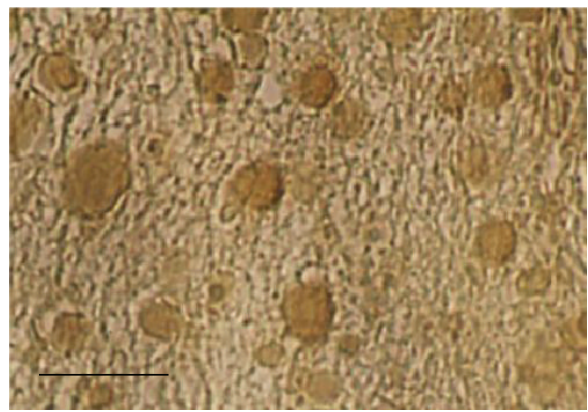

(f)

FIGURE 3: Frontal section photographs of the human SFO immunostained with anti-vasopressin. ((a), (c), and (e)) NO-SIADH case; ((b), (d), and (f)) SIADH case. ChP: choroid plexus, F: fornix, and SFO: subfornical organ. Bar: (a), (b) $=200 \mu \mathrm{m}$; (c), (d) $=60$.

\section{Discussion}

The clinical history of the SIADH patient showed a periodically progressive increase in plasma vasopressin that closely correlated with greater plasma sodium, and at other times the patient showed normal or lower levels of VAS corresponding to normal or lower levels of plasma sodium, which could correspond to type $\mathrm{C}$ of the Robertson classification [18]. Robertson divided the SIADH into three types of abnormal vasopressin (VAS) release during hypertonic saline infusion $[14,18]$ : type A, high, inconsistent fluctuations unrelated to increases in plasma sodium; type $\mathrm{B}$, a slow regular release, which is also unaltered by increases in plasma sodium; type C, a quick progressive increase in plasma VAS that closely correlates with plasma sodium as it rises towards the normal range; there is also another kind, type $\mathrm{D}$, that appears in a low percentage of patients, where there is no demonstrable defect in the osmoregulation of VAS and the cause of inappropriate antidiuresis is unclear $[18,19]$.
The SIADH pathophysiology consists of an absolute increase in body water [19]. This increase depends on an excessive water intake that overwhelms the restricted renal ability of diluting urine and mounting compensatory diuresis due to vasopressin dysregulation. A previous work [20] showed that vasopressin immunoreactive material was less intensive and was present in a lower number of cells and fibres in the SIADH case where it was mainly found in the whole supraoptic nucleus and the magnocellular part of the paraventricular hypothalamic nucleus. The low intensity of VAS in the case of SIADH could mean an increase in VAS release owing to variations in the vasopressin receptor, since other studies [21] have described cases, whose clinical presentation and laboratory findings were consistent with SIADH but which exhibited unmeasurable VAS levels on repeated occasions that seems to be due to an activating mutation of the vasopressin receptor V2 (V2R). But, in other patients, this may be due to abnormal control of aquaporin-2 


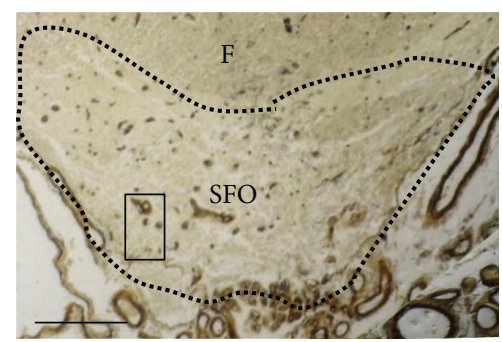

(a)

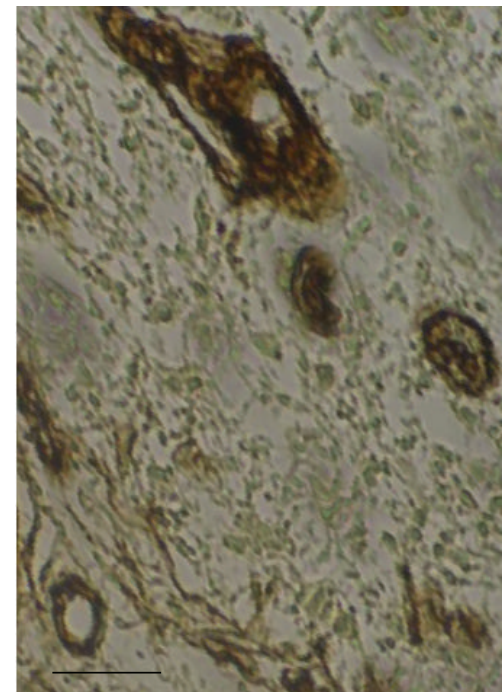

(c)

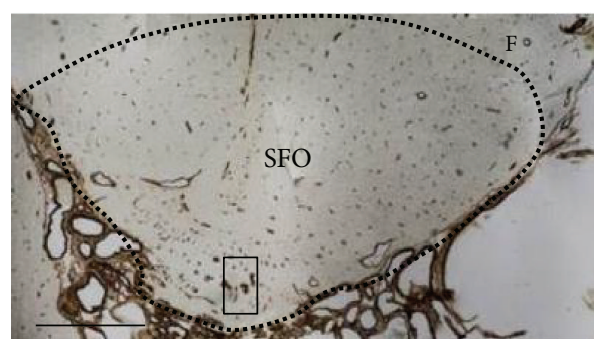

(b)

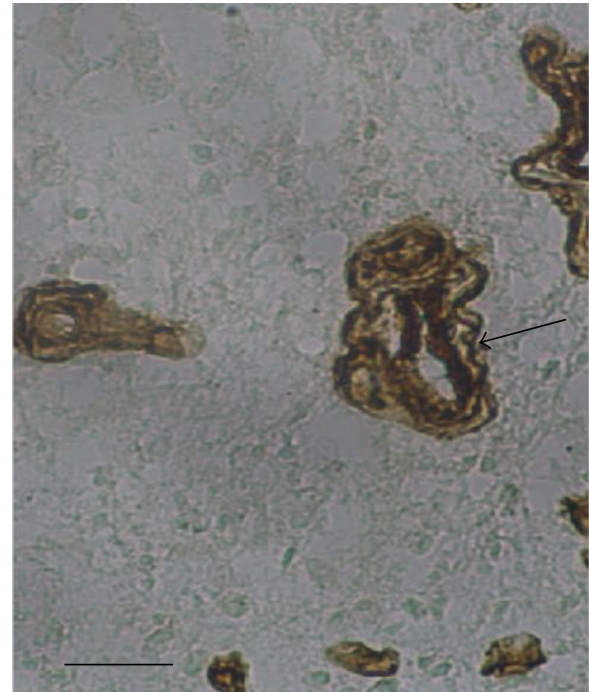

(d)

FIGURE 4: Frontal section photographs of the human SFO immunostained with anti-collagen-IV. ((a), (c)) NO-SIADH case; ((b), (d)) SIADH case. ChP: choroid plexus, F: fornix, and SFO: subfornical organ. Bar: (a), (b) $=200 \mu \mathrm{m}$; (c), (d) =60.

water channels in renal collecting tubules or the production of an antidiuretic principle other than VAS [18].

\section{Conclusion}

In conclusion, the results of this case show a weak and redistributed AGII immunoreactivity in the SFO and a variation in the vascular wall and lumen. We hypothesize that these physiological features may be the result of a dysfunction or hyperfunction of the SFO where there would be an increase in angiotensinergic stimulus from the SFO to the paraventricular (PVN) and supraoptic (SPO) nucleus inducting intensification in VAS production and release at the level of the PVN, SPO, and pituitary posterior lobe. This hypothesis is based on the study of only one SFO and case of SIADH, however, and further research is needed to confirm these findings.

\section{Conflict of Interests}

The authors declare that there is no conflict of interests regarding the publication of this paper.

\section{Acknowledgments}

This work was supported by "Fundación Canaria de Instituto de Investigación y Ciencias de Puerto del Rosario (INIPRO)" Project no. 02/10 and "Universidad de La Laguna" Project no. $2013 / 0001341$.

\section{References}

[1] R. Jiménez, J. Casado-Flores, M. Nieto, and M. A. García-Teresa, "Cerebral salt wasting syndrome in children with acute central nervous system injury," Pediatric Neurology, vol. 35, no. 4, pp. 261-263, 2006.

[2] T. Çelik, O. Tolunay, I. Tolunay, and Ü. Çelik, "Cerebral salt wasting in status epilepticus: two cases and review of the literature," Pediatric Neurology, vol. 50, no. 4, pp. 397-399, 2014.

[3] W. B. Schwartz, W. Bennett, S. Curelop, and F. C. Bartter, "A syndrome of renal sodium loss and hyponatremia probably resulting from inappropriate secretion of antidiuretic hormone," The American Journal of Medicine, vol. 23, no. 4, pp. 529$542,1957$.

[4] I. Cabaj-Wiater and I. Jakubowska, "Hyponatremia in syndrome of inappropiate antidiuretic hormone secretion-cases report," Polski Merkuriusz Lekarski, vol. 25, no. 147, pp. 247-249, 2008. 
[5] G. Decaux and W. Musch, "Clinical laboratory evaluation of the syndrome of inappropriate secretion of antidiuretic hormone," Clinical Journal of the American Society of Nephrology, vol. 3, no. 4, pp. 1175-1184, 2008.

[6] J. B. Sorensen, M. K. Andersen, and H. H. Hansen, "Syndrome of inappropriate secretion of antidiuretic hormone (SIADH) in malignant disease," Journal of Internal Medicine, vol. 238, no. 2, pp. 97-110, 1995.

[7] H. E. de Wardener, "The hypothalamus and hypertension," Physiological Reviews, vol. 81, no. 4, pp. 1599-1658, 2001.

[8] M. F. R. Ferrari, E. F. Coelho, K. L. G. Farizatto, G. Chadi, and D. R. Fior-Chadi, "Modulation of tyrosine hydroxylase, neuropeptide $\mathrm{Y}$, glutamate, and substance $\mathrm{P}$ in ganglia and brain areas involved in cardiovascular control after chronic exposure to nicotine," International Journal of Hypertension, vol. 2011, Article ID 216464, 9 pages, 2011.

[9] E. M. Carmona-Calero, H. Perez-Gonzalez, I. Martínez-Peña Y Valenzuela et al., "Effect of the arterial hypertension and captopril treatment on the angiotensin II content in the subfornical organ. A study in SHR rats," Histology and Histopathology, vol. 20, no. 1, pp. 135-138, 2005.

[10] I. González-Marrero, L. Castañeyra-Ruiz, H. de Paz-Carmona, A. Castañeyra-Ruiz, J. M. González-Toledo, and E. M. Carmona-Calero, "Variaciones del sistema angiotensinavasopresina hipotalámico ante hipertensión arterial y su tratamiento con captopril," Majorensis, vol. 4, no. 1, pp. 15-18, 2008.

[11] B. Mayinger and J. Hensen, "Nonpeptide vasopressin antagonists: a new group of hormone blockers entering the scene," Experimental and Clinical Endocrinology and Diabetes, vol. 107, no. 3, pp. 157-165, 1999.

[12] M. T. Panayotacopoulou, E. Goudsmit, J. J. van Heerikhuize, and D. F. Swaab, "Simultaneous detection of tyrosine hydroxylase-immunoreactivity and vasopressin mRNA in neurons of the human paraventricular and supraoptic nucleus," Brain Research, vol. 855, no. 1, pp. 181-185, 2000.

[13] M. Macova, J. Pavel, and J. M. Saavedra, "A peripherally administered, centrally acting angiotensin II AT2 antagonist selectively increases brain AT1 receptors and decreases brain tyrosine hydroxylase transcription, pituitary vasopressin and ACTH," Brain Research, vol. 1250, pp. 130-140, 2009.

[14] K. Kaneko, T. Shioya, and K. Yabuta, "Inappropriate secretion of antidiuretic hormone and transient hypertension associated with Guillain-Barre syndrome," Pediatric Neuroscience, vol. 15, no. 5, pp. 257-259, 1989.

[15] A. Castaneyra-Perdomo, G. Meyer, E. Carmona-Calero et al., "The effects of chronic administration of captopril on the mouse subfornical organ and area postrema," Experimental Neurology, vol. 120, no. 1, pp. 145-148, 1993.

[16] A. Castaneyra-Perdomo, G. Meyer, and D. J. Heylings, "Early development of the human area postrema and subfornical organ," Anatomical Record, vol. 232, no. 4, pp. 612-619, 1992.

[17] J. P. Coble, R. F. Johnson, M. D. Cassell, A. K. Johnson, J. L. Grobe, and C. D. Sigmund, "Activity of protein kinase c$\alpha$ within the subfornical organ is necessary for fluid intake in response to brain angiotensin," Hypertension, vol. 64, pp. 141148, 2014.

[18] G. L. Robertson, "Regulation of arginine vasopressin in the syndrome of inappropriate antidiuresis," The American Journal of Medicine, vol. 119, supplement 1, no. 7, pp. S36-S42, 2006.

[19] P. Esposito, G. Piotti, S. Bianzina, Y. Malul, and A. Dal Canton, "The syndrome of inappropriate antidiuresis: pathophysiology, clinical management and new therapeutic options," Nephron Clinical Practice, vol. 119, no. 1, pp. c62-c73, 2011.

[20] E. M. Carmona-Calero, L. Castañeyra-Ruiz, I. GonzalezMarrero et al., "Vasopressin, angiotensin II and tyrosinehydroxylase expression in the hypothalamus of the syndrome of inappropriate ADH: a case report," The Open Pathology Journal, vol. 6, no. 1, pp. 1-7, 2012.

[21] S. E. Gitelman, B. J. Feldman, and S. M. Rosenthal, "Nephrogenic syndrome of inappropriate antidiuresisa novel disorder in water balance in pediatric patients," The American Journal of Medicine, vol. 119, supplement 1, no. 7, pp. S54-S58, 2006. 


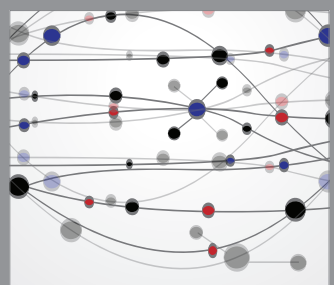

The Scientific World Journal
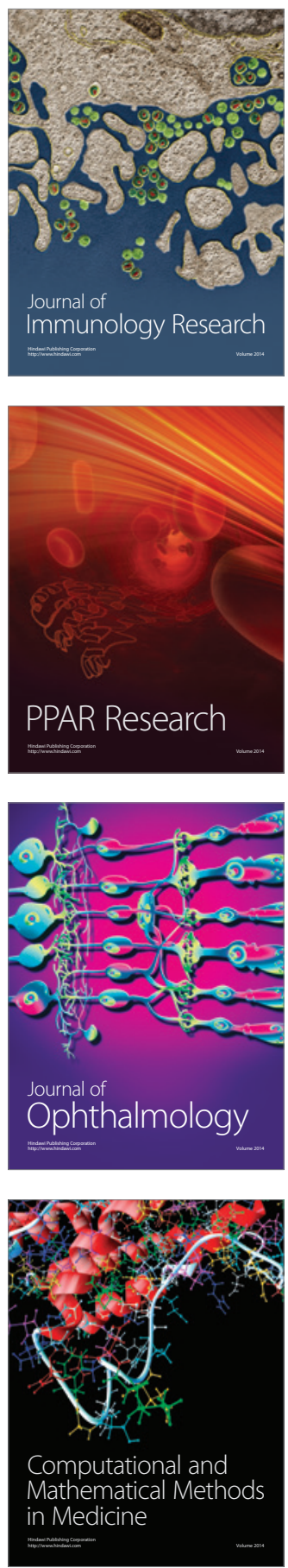

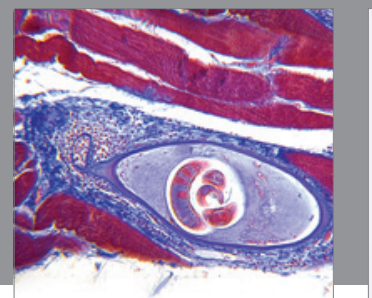

Gastroenterology

Research and Practice
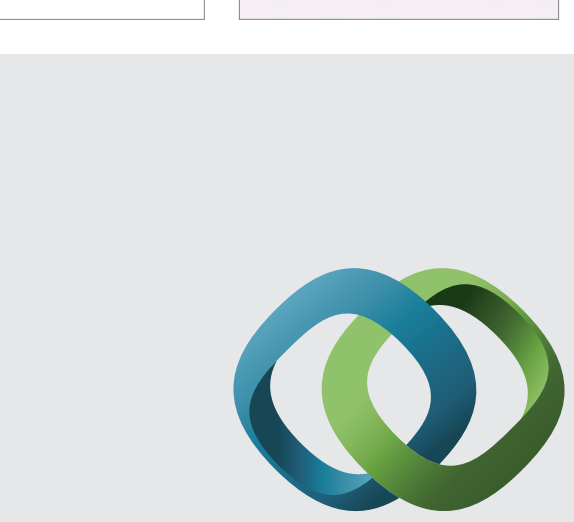

\section{Hindawi}

Submit your manuscripts at

http://www.hindawi.com
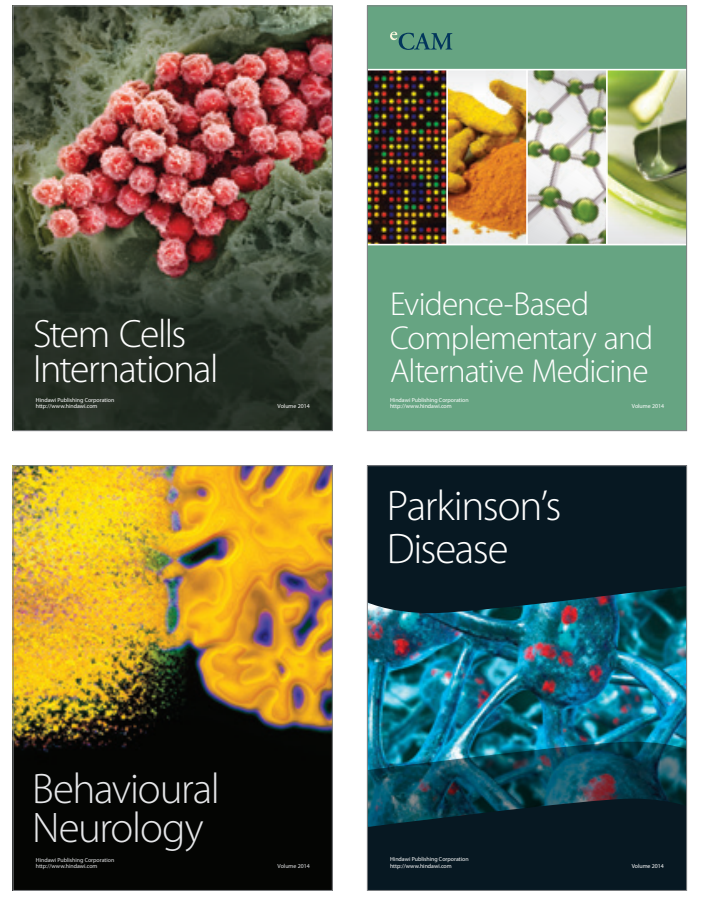
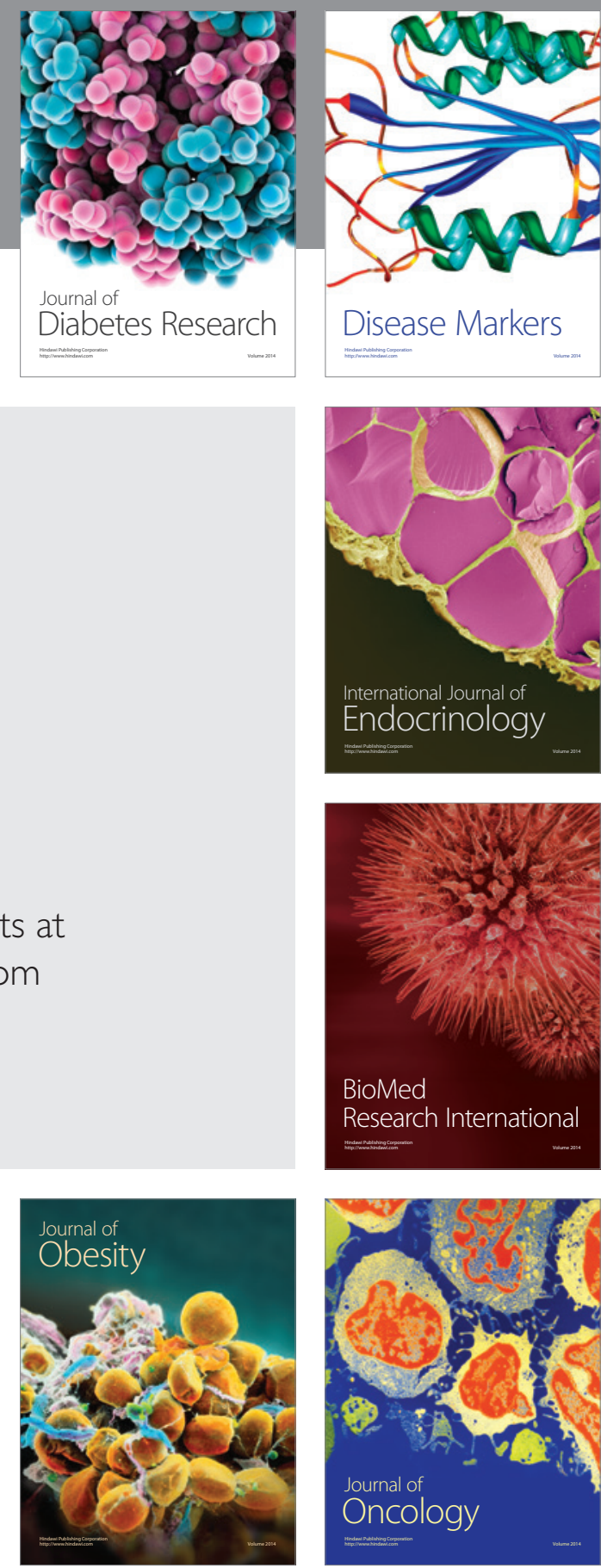

Disease Markers
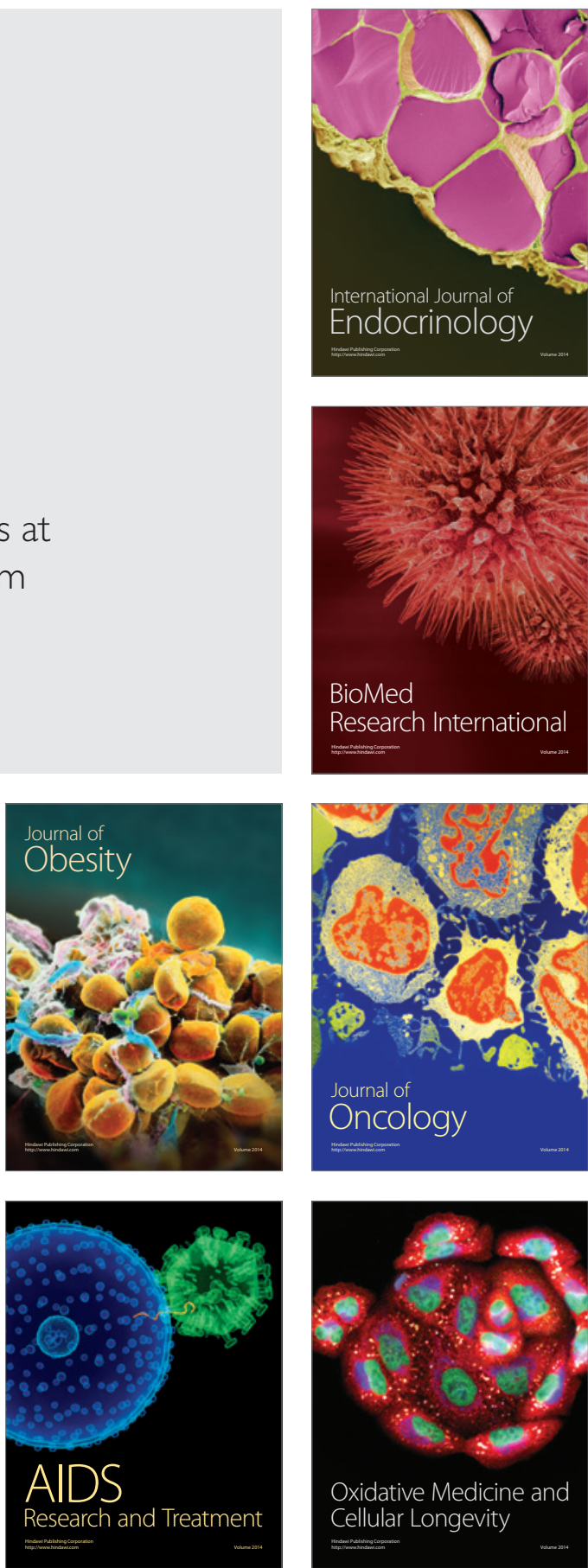